University of Montana

ScholarWorks at University of Montana

Rural Institute Journal Articles

$11-2001$

\title{
Abuse Assessment Screen-Disability (AAS-D): Measuring Frequency, Type, and Perpetrator of Abuse toward Women with Physical Disabilities
}

\author{
Judith McFarlane \\ Texas Woman's University \\ Rosemary B. Hughes \\ University of Montana - Missoula, rhughes@ruralinstitute.umt.edu \\ Margaret A. Nosek \\ Baylor College of Medicine \\ Janet Y. Groff \\ University of Texas-Houston \\ Nancy Swedlend \\ Baylor College of Medicine \\ See next page for additional authors \\ Follow this and additional works at: https://scholarworks.umt.edu/ruralinst_pubs \\ Part of the Rehabilitation and Therapy Commons \\ Let us know how access to this document benefits you.
}

\section{Recommended Citation}

This is a copy of an article published in the JOURNAL OF WOMEN'S HEALTH AND GENDER-BASED MEDICINE @ 2001 copyright Mary Ann Liebert, Inc.; JOURNAL OF WOMEN'S HEALTH AND GENDERBASED MEDICINE is available online at: http://online.liebertpub.com.

This Article is brought to you for free and open access by ScholarWorks at University of Montana. It has been accepted for inclusion in Rural Institute Journal Articles by an authorized administrator of ScholarWorks at University of Montana. For more information, please contact scholarworks@mso.umt.edu. 


\section{Authors}

Judith McFarlane, Rosemary B. Hughes, Margaret A. Nosek, Janet Y. Groff, Nancy Swedlend, and Patricia Dolan Mullen 


\title{
Abuse Assessment Screen-Disability (AAS-D): Measuring Frequency, Type, and Perpetrator of Abuse toward Women with Physical Disabilities
}

\author{
JUDITH McFARLANE, Dr.P.H., ${ }^{1}$ ROSEMARY B. HUGHES, Ph.D., ${ }^{2}$ \\ MARAGET A. NOSEK, Ph.D., ${ }^{2}$ JANET Y. GROFF, M.D., Ph.D., ${ }^{3}$ \\ NANCY SWEDLEND, Ph.D., ${ }^{2}$ and PATRICIA DOLAN MULLEN, Dr.P.H. ${ }^{4}$
}

\begin{abstract}
An interview questionnaire was presented to a multiethnic sample of 511 women, age 18-64 years, at public and private specialty clinics to determine the frequency, type, and perpetrator of abuse toward women with physical disabilities. The four-question Abuse Assessment Screen-Disability (AAS-D) instrument detected a $9.8 \%$ prevalence (50 of 511) of abuse during the previous 12 months. Using two standard physical and sexual assault questions, $7.8 \%$ of the women (40 of 511) reported abuse. The two disability-related questions detected an additional $2.0 \%$ of the women (10 of 511) as abused. Women defining themselves as other than black, white, or Hispanic (i.e., Asian, mixed ethnic background) were more likely to report physical or sexual abuse or both, whereas disability-related abuse was reported almost exclusively by white women. The perpetrator of physical or sexual abuse was most likely to be an intimate partner. Disability-related abuse was attributed equally to an intimate partner, a care provider, or a health professional. This study concludes that both traditional abuse-focused questions and disability-specific questions are required to detect abuse toward women with physical disabilities.
\end{abstract}

\section{INTRODUCTION}

A BUSE AGAINST WOMEN IS EPIDEMIC,,$^{1,2}$ affects health, ${ }^{3-5}$ and contributes significantly to the cost of medical care. 6,7 The Council on Scientific Affairs of the American Medical Association $(\mathrm{AMA})^{8}$ lists four steps to increase detection of abuse among female patients, commencing with a routine assessment documented in the medical record. The importance of designated questions to ensure abuse assessment and documentation is well established. One study showed that identification of abuse increased to $11.6 \%$ prevalence when one question about assault by an intimate partner was added to the health history form in a primary care setting. In contrast, no identifications resulted when questioning was left to the discretion of healthcare providers. ${ }^{9}$ The use of a specific screening question in prenatal clinics to assess for abuse during pregnancy resulted in a $9 \%$ higher detection rate than the routine social service interview. ${ }^{10}$ In a recent study using a four-

\footnotetext{
${ }^{1}$ Texas Woman's University, Houston, Texas.

${ }^{2}$ Baylor College of Medicine, Houston, Texas.

${ }^{3}$ University of Texas-Houston Medical School, Houston, Texas.

${ }^{4}$ University of Texas-Houston School of Public Health, Houston, Texas.

This research was supported by the National Center for Injury Prevention and Control (Ro4/CCR614142-03).
} 
1. Within the last year, have you been hit, slapped, kicked, pushed, shoved, or otherwise physically hurt by someone? YES $\mathrm{NO}$

If YES, who? (Circle all that apply)

Intimate partner

Care provider

Health professional

Family member

Other

Please describe:

2. Within the last year, has anyone forced you to have sexual activities?

YES

$\mathrm{NO}$

If YES, who? (Circle all that apply)

Intimate partner

Care provider

Health professional

Family member

Other

Please describe:

3. Within the last year, has anyone prevented you from using a wheelchair, cane, respirator, or other assistive devices? YES

$\mathrm{NO}$

If YES, who? (Circle all that apply)

Intimate partner

Care provider

Health professional

Family member

Other

Please describe:

4. Within the last year, has anyone you depend on refused to help you with an important personal need, such as taking your medicine, getting to the bathroom, getting out of bed, bathing, getting dressed, or getting food or drink?

YES

$\mathrm{NO}$

If YES, who? (Circle all that apply)

Intimate partner

Care provider

Health professional

Family member

Other

Please describe:

FIG. 1. Abuse Assessment Screen-Disability (AAS-D) (circle YES or NO).

question abuse assessment screen, the frequency of documented assessments increased from 0 to $88 \%$, and detection of abuse increased from $0.8 \%$ to $7 \% .{ }^{11}$ Clearly, routine assessment for abuse using designated questions increases detection.

It is estimated that 26 million American women, or nearly $20 \%$ of the population of women, live with a physical disability. ${ }^{12}$ One national mail survey found that the same proportion of women with physical disabilities $(n=$ 439), compared with women without physical disabilities $(n=421)$, reported being physically $(35.5 \%$ vs. $35.6 \%)$ or sexually $(39.9 \%$ vs. $37.1 \%)$ abused. ${ }^{13}$ Perpetrator relationship showed no differences between groups, with intimate partners being the primary offender. However, women with physical disabilities were more likely to experience physical $(1.6 \%$ vs. $0 \%)$ or sexual $(2.3 \%$ vs. $0.5 \%$ ) abuse by attendants and reported more sexual abuse by healthcare providers $(4.8 \%$ vs. $2.4 \%$ ). Additionally, women with physical disabilities had experienced the abuse for a significantly longer period of time than women without physical disability (7.4 years vs. 5.6 years). The study concluded that women with physical disabilities are most at risk for abuse of all types from their intimate partners and experience abuse in the same proportion as women without physical disabilities. However, women with physical disabilities are more likely to experience physical or sexual abuse by attendants and healthcare providers.

Abuse assessment tools that focus on intimate partner physical or sexual abuse are insufficient for the range of abuse experienced by women with physical disabilities. Therefore, the Abuse 
Assessment Screen-Disability (AAS-D) tool was developed and tested in specialty clinics for women with disabilities. To our knowledge, the effectiveness of direct clinical assessment of abuse toward women with physical disabilities has not been evaluated.

\section{MATERIALS AND METHODS}

To determine the frequency, type, and perpetrator of abuse toward women with a physical disability, 511 women were assessed for abuse using the AAS-D tool (Fig. 1). Questions 1 and 2 of the AAS-D are taken directly from the AAS, a widely used assessment instrument with established reliability and concurrent validity. ${ }^{14,15}$ Questions 3 and 4 of the AAS-D were developed based on the results of the national study ${ }^{13}$ using qualitative interviews with abused disabled women and after consultation with experts in the field of abuse assessment.

Participation was limited to English-speaking and Spanish-speaking women with physical disabilities who were 18-64 years of age; were diagnosed with a physical disability that limited one or more major life activities, including mobility and self-care/home management; and had no known cognitive or communication impairments or mental health problems that would significantly diminish their ability to respond to the questions during the interview. Five specialty clinics that serve women with physical disabilities provided the setting for data collection.

After approval by the agencies and institutional review boards for human subjects, sampling proceeded as follows. Women using the specialty clinics who met study criteria were informed of the study by clinic staff. The project staff escorted interested women to a private room where the study was explained in English or Spanish according to the woman's language preference. A sample of 511 women met the study criteria and gave informed consent. Approximately 20 women refused to participate and be screened. Lack of time was the most common reason for not participating. Basic demographic information was gathered before administration of the fourquestion AAS-D. Women were asked to self-define their ethnic affiliation. All instruments were administered orally by the interviewer and offered in English or Spanish. All women were offered written information on the cycle of violence and community resources for law enforcement, safe shelter, and legal aid.

\section{RESULTS}

The demographic characteristics and abuse status of the 511 disabled women are shown in Table 1. Women defining themselves as "Other" were primarily of mixed ethnicity. Most women were over age 35 , and $42 \%$ were married. Although al-

Table 1. Characteristics of 511 Disabled Women

\begin{tabular}{|c|c|c|c|c|c|}
\hline Characteristic & $\begin{array}{l}\text { Black, \% } \\
(\mathrm{n}=135)\end{array}$ & $\begin{array}{l}\text { Hispanic, } \% \\
(\mathrm{n}=112)\end{array}$ & $\begin{array}{l}\text { White, \% } \\
(\mathrm{n}=225)\end{array}$ & $\begin{array}{l}\text { Other, } \% \\
(\mathrm{n}=37)\end{array}$ & $\begin{array}{c}\text { Total, } \% \\
(\mathrm{n}=509)^{\mathrm{a}}\end{array}$ \\
\hline \multicolumn{6}{|l|}{ Age, years } \\
\hline $18-34$ & 21.5 & 30.7 & 8.4 & 10.9 & 16.9 \\
\hline $35-44$ & 25.2 & 22.5 & 21.0 & 40.5 & 23.8 \\
\hline $45-54$ & 25.2 & 33.3 & 43.8 & 37.8 & 36.3 \\
\hline $55-64$ & 28.1 & 13.5 & 26.8 & 10.8 & 23.0 \\
\hline Married & 29.5 & 33.0 & 52.0 & 48.6 & 41.8 \\
\hline \multicolumn{6}{|l|}{ Education, years } \\
\hline 0-11 & 20.9 & 64.9 & 8.6 & 19.4 & 25.3 \\
\hline $12 / G E D$ & 38.1 & 21.6 & 20.9 & 27.8 & 26.1 \\
\hline$\geq 13$ & 41.0 & 13.5 & 70.5 & 52.8 & 48.6 \\
\hline \multicolumn{6}{|l|}{ Type of abuse } \\
\hline Physical/sexual & 10.4 & 8.9 & 4.4 & 16.2 & 7.8 \\
\hline Disability related & 0.7 & 0.9 & 3.6 & 0 & 2.0 \\
\hline
\end{tabular}

${ }^{a}$ Data on ethnicity are missing for 2 women. 
Table 2. Perpetrator and Type of Abuse to Disabled Women

\begin{tabular}{lcc}
\hline Perpetrator $^{\mathrm{a}}$ & $\begin{array}{c}\text { Physical/sexual abuse } \\
\mathrm{n}=40\end{array}$ & $\begin{array}{c}\text { Disability-related abuse } \\
\mathrm{n}=10\end{array}$ \\
\hline Intimate partner & 24 & 3 \\
Care provider & 3 & 3 \\
Health provider & 6 & 3 \\
Family member & 9 & 2 \\
Other (stranger, neighbor) & 7 & 1 \\
\hline
\end{tabular}

aSome women were abused by perpetrators in more than one category.

most half of the women $(48.6 \%)$ reported education beyond high school, only $21.5 \%$ were gainfully employed. Mean duration of disability was 13.3 years $(\mathrm{SD}=12.9)$, with $78 \%$ of the women requiring assistive devices (e.g., cane, walker, wheelchair). Using the four-question AAS-D, $9.8 \%$ of the women (50 of 511) reported abuse. Using questions 1 and 2, only $7.8 \%$ of the women (40 of 511) reported abuse. When the two disability-related questions were added, an additional $2 \%$ of the population (10 women) reported abuse. The 37 women defining themselves other than black, white, or Hispanic were more likely to report physical or sexual abuse or both. Of the 10 women who reported disability-related abuse, 8 identified themselves as Caucasian. An intimate partner was the primary perpetrator of physical or sexual abuse (Table 2). Disability-related abuse was attributed almost equally to an intimate partner, a care provider, or a health professional (Table 2).

\section{DISCUSSION}

When a sample of 511 black, Hispanic, and white women with physical disabilities was assessed for abuse with four clinical questions, 1 in 10 disabled women reported abuse. The twoquestion AAS detected $8 \%$ of the abused women, and two disability-related questions found an additional $2 \%$. The perpetrator was more likely to be an intimate partner in the case of physical and sexual abuse. For disability-related abuse, no single perpetrator type emerged.

Both traditional abuse-focused and disabilityspecific questions are required to measure abuse toward women with physical disabilities accurately. The level of abuse measured with questions 1 and 2 of the AAS-D is similar to the prevalence rates among women in primary care settings. ${ }^{16,17}$ No clinical sample exists for comparison of disability-related abuse. Using a traditional two-question screening tool, only $80 \%$ of the abused women would have been detected.

The generalizability of the findings from this study is limited by the cross-sectional research design and the use of a convenience sample of predominantly urban disabled clinic patients. Replication with the AAS-D is needed in rural geographic areas, as well as with more severely disabled women who lack outpatient clinic access. Furthermore, the study relies entirely on self-reports, which may underreport or overreport because of inadequate recall or lack of voluntary disclosure. No attempt was made to confirm any of the information independently. Finally, the goal of this study was not to validate the AAS-D. Despite these limitations, this study documents the usefulness of an abuse assessment tool designed for women with physical disabilities.

\section{CONCLUSIONS}

The implications of our study are simple and straightforward. Four assessment questions asked in a private setting revealed that 1 in 10 disabled women in this population had been abused within the last year. Research has documented the importance of an interview questionnaire vs. self-report for abuse detection. Self-report for abuse, using the AAS, was measured against primary provider assessment. Approximately $8 \%$ of women self-reported abuse on a standard medical history intake form, but when asked the same abuse assessment questions in a private interview, $29 \%$ of the women reported abuse. ${ }^{18}$

More than a decade ago, the Surgeon General called for routine assessment of abuse of pregnant women. ${ }^{19}$ Healthy People 2000: Midcourse Re- 
view and 1995 Revisions called for the training of healthcare professionals to address the needs of victims of violence. ${ }^{20}$ Reducing the rate of physical assault by current or former intimate partners is specifically included in Healthy People $2010 \mathrm{ob}-$ jectives. ${ }^{21}$ Public health officials recommend that standard protocols be implemented in healthcare settings in the belief that "early identification, supportive education, effective referral, and ongoing support and follow-up for abused women at primary care sites could eventually reduce the prevalence of abusive injury by up to $75 \%$." 22

The American College of Obstetricians and Gynecologists ${ }^{23,24}$ has emphasized the existence of partner violence and the need for routine assessment of all women. ${ }^{25}$ The position of the American Academy of Family Physicians is that family physicians must be able to recognize and know how to treat family violence. ${ }^{26}$ Specific protocols for intervening in cases of abuse during pregnancy $^{27}$ and for identification, assessment, and intervention in healthcare settings have been published. $^{28}$

Commonly, clinic visits are the only time that disabled women come into contact with healthcare providers. This study documents that four simple clinical screening questions can detect abuse. Assessment for physical, sexual, and disability-related abuse must be standard care for disabled women.

\section{ACKNOWLEDGMENTS}

We extend appreciation to JoAnn Thierry of the Office on Disability and Health Programs for her encouragement. We also thank the patients and medical staff of the Harris County Hospital District, Baylor-Methodist Multiple Sclerosis Clinic, and the Institute of Rehabilitation Research for the privilege of working with them.

\section{REFERENCES}

1. Collins KS, Schoen C, Joseph S, Duchon L, Simantov E, Yellowitz M. The Commonwealth Fund 1998 survey of women's health. New York: Louis Harris \& Associates, 1999.

2. Greenfield LA, Rand MR, Craven D, et al. Violence by intimates: Analysis of data on crimes by current or former spouses, boyfriends, and girlfriends. Washington, DC: U.S. Department of Justice; 1998 (NCJ No. 167237).
3. Scholle SH, Rost KM, Golding JM. Physical abuse among depressed women. J Gen Intern Med 1998;13:607.

4. Silva C, McFarlane J, Soeken K, Parker B, Reel S. Symptoms of post-traumatic stress disorder in abused women in a primary care setting. J Wom Health 1997; 6:543.

5. Kilpatrick DG, Acierno R, Resnick HS, Saunders BE, Best CL. A 2-year longitudinal analysis of the relationships between violent assault and substance use in women. J Consult Clin Psychol 1997;65:834.

6. American Medical Association. Domestic violence begets other problems of which physicians must be aware to be effective. JAMA 1990;264:940.

7. Wisner CL, Gilmer TP, Saltzman LE, Zink TM. Intimate partner violence against women: Do victims cost health plans more? J Fam Pract 1999;48:439.

8. Council on Scientific Affairs, American Medical Association. Violence against women: Relevance for medical practitioners. JAMA. 1992;267:3184.

9. Freund KM, Bak SM, Blackhall L. Identifying domestic violence in primary care. J Gen Intern Med. 1996;11:44.

10. Norton LB, Peipert JF, Zierler S, Lima B, Hume L. Battering in pregnancy: An assessment of 2 screening methods. Obstet Gynecol. 1995;85:321.

11. Wiist WH, McFarlane J. The effectiveness of an abuse assessment protocol in public health prenatal clinic. Am J Public Health. 1999;89:1217.

12. McNeil JM. Americans with disabilities: 1994-95. Current population reports, P7061:3-6. Washington, DC: Bureau of the Census, 1997.

13. Young M, Nosek MA, Howland D, Chanpong G, Rintala DH. Prevalence of abuse of women with physical disabilities. Arch Phys Med Rehabil. 1997;78:34.

14. McFarlane J, Parker B, Soeken K, Bullock L. Assessing for abuse during pregnancy: Severity and frequency of injuries and associated entry into prenatal care. JAMA 1992; 267:3176.

15. Soeken K, McFarlane J, Parker B, Lominack MC. The Abuse Assessment Screen: A clinical instrument to measure frequency, severity, and perpetrator of abuse against women. In: Campbell JC, ed. Empowering survivors of abuse: Health care for battered women and their children. Thousand Oaks, CA: Sage, 1998.

16. Elliott BA, Johnson MMP. Domestic violence in a primary care setting. Arch Fam Med 1995;4:113.

17. McCauley J, Kern DE, Kolodner K, Derogatis LR, Bass EB. Relation of low-severity violence to women's health. J. Gen Intern Med. 1998;13:687.

18. McFarlane J, Christoffel K, Bateman L, Miller V, Bullock L. Assessing for abuse: Self-report versus nurse interview. Public Health Nurs. 1991;8:245.

19. Surgeon General's workshop on violence and public health. Washington, DC: U.S. Public Health Service, 1985.

20. Healthy people 2000: Midcourse review and 1995 revisions. Washington, DC: U.S. Department of Health and Human Services, 1995.

21. Healthy people 2010. Conference edition. Washington, DC: U.S. Department of Health and Human Services, No. 017-001-00547-9, January 2000. 
22. Rosenbery M, Fenley MA. Violence in America. A public health approach. New York: Oxford University Press, 1991:150.

23. American College of Obstetricians and Gynecologists. The battered woman. Washington, DC: American College of Obstetricians and Gynecologists, 1989. Technical Bulletin No. 124.

24. American College of Obstetricians and Gynecologists. Domestic violence. Washington, DC: American College of Obstetricians and Gynecologists, 1995. Technical Bulletin No. 209.

25. Chez RA, Jones RF III. The battered woman. Am J Obstet Gynecol. 1995;173:677.

26. American Academy of Family Physicians, Commission on Special Issues and Clinical Interests. Family violence: An AAFP white paper. Am Fam Phys 1994; 50:1636.
27. McFarlane J, Parker B, Cross B. Abuse during pregnancy: A protocol for prevention and intervention. New York: National March of Dimes Birth Defects Foundation, 2001.

28. Warshaw C. Identification, assessment and intervention with victims of domestic violence. In: Warshaw $\mathrm{C}$, ed. Identification, assessment and intervention with victims of domestic violence: Improving the healthcare response to domestic violence, 2nd ed. San Francisco: Family Violence Prevention Fund, 1996:49.

Address reprint requests to: Judith McFarlane, Dr.P.H. Texas Woman's University 1130 M.D. Anderson Boulevard Houston, TX 77030 